\title{
Urine interleukin-6, interleukin-8 and transforming growth factor $\beta 1$ in infants with urinary tract infection and asymptomatic bacteriuria
}

\author{
GRAŻYNA KRZEMIEŃ, AGNIESZKA SZMIGIELSKA, AGNIESZKA TURCZYN, \\ MAEGORZATA PAŃCZYK-TOMASZEWSKA \\ Department of Pediatrics and Nephrology, Medical University of Warsaw, Poland
}

\begin{abstract}
Introduction: Urinary tract infection (UTI) occurs in $1.1 \%$ of girls and $1.4 \%$ of boys during the first year of life. Asymptomatic bacteriuria $(A B U)$ is usually detected incidentally in $0.9 \%$ of girls and $2.5 \%$ of boys at this age. The aim of the study was to assess the usefulness of measurement of pro-inflammatory urine interleukin (IL)- 6 and IL-8 concentrations and anti-inflammatory transforming growth factor $\beta 1$ (TGF- $\beta 1)$ level in infants with febrile UTI, non-febrile UTI and ABU.

Material and methods: A total of 35 children, mean age $6.14 \pm 3.47$ months, were divided into three groups: group I-febrile UTI $(n=13)$, group II - non-febrile UTI $(n=13)$ and group III $-A B U(n=9)$. At the time of enrollment urine $I L-6, I L-8, T G F-\beta 1$ and serum $C$-reactive protein $(C R P)$, erythrocyte sedimentation rate (ESR), and white blood cell count (WBC) were measured. Renal ultrasound was performed in all children, ${ }^{99 m}$ Tc-dimercaptosuccinic acid scintigraphy (DMSA) and voiding cystourethrography in children with UTI.

Results: Urine concentrations of IL-6 and IL-8 were significantly higher in febrile UTI compared to those with non-febrile UTI and $A B U(p<0.5, p<0.01)$ and positively correlated with CRP, ESR and WBC $(p<0.01)$. Urine levels of TGF- $\beta 1$ were significantly higher in children with febrile UTI compared to those with $A B U(p<0.05)$ and positively correlated with $W B C(p<0.01)$. Inflammatory changes in the DMSA scan were detected in $66.6 \%$ of children with UTI. No significant difference in frequency of an abnormal DMSA scan compared to a normal scan was found in groups with febrile and non-febrile UTI. No relations between urine cytokines, systemic inflammatory markers and changes in DMSA scan were observed. The cutoff value for detection of inflammatory changes in the DMSA scan for IL-8 was $120 \mathrm{pg} / \mathrm{mg}$ creatinine $(\mathrm{Cr})$ and $40 \mathrm{pg} / \mathrm{mg} \mathrm{Cr}$ for TGF- $\beta 1$. Based on this value, the sensitivity for $I L-8$ was $58.3 \%$, specificity $100 \%$ and for $T G F-\beta 166.7 \%$ and $83.7 \%$, respectively.

Conclusions: We found significant differences in children with febrile UTI and ABU regarding urine $I L-6, I L-8$ and TGF- $\beta 1$ levels. Urine cytokines and systemic inflammatory markers do not differentiate between upper and lower UTI in infants.
\end{abstract}

Key words: urinary tract infection, asymptomatic bacteriuria, interleukin-6, interleukin-8, transforming growth factor $\beta 1$.

(Cent Eur J Immunol 2016; 41 (3): 260-267)

\section{Introduction}

Urinary tract infection (UTI) is one of the most common bacterial infections in children and occurs in $1.1 \%$ of girls and $1.4 \%$ of boys in the first year of life. Urinary tract infection is responsible for $5 \%$ of all episodes of fever in infants $[1,2]$. Infection can involve kidney pa- renchyma in pyelonephritis or can be limited only to the lower urinary tract. Asymptomatic bacteriuria (ABU) is usually detected incidentally in $0.9 \%$ of girls and $2.5 \%$ of boys at this age $[3,4]$. Asymptomatic bacteriuria usually recovers spontaneously and does not need treatment except in newborns, pre-school children with abnormalities

Correspondence: Agnieszka Szmigielska, MD, PhD, Department of Pediatrics and Nephrology, Medical University of Warsaw, Żwirki i Wigury 63 A, 02-091 Warsaw, Poland, e-mail: agnieszka.szmigielska@wum.edu.pl Submitted: 12.06.2016; Accepted: 26.07.2016 
in the urinary tract and children before an invasive genitourinary procedure [5].

Cytokines are small, soluble proteins produced by various cells in response to infections and inflammation. Interleukin (IL)-6 is a pro-inflammatory cytokine, the concentration of which increases in the early stage of bacterial infection. Interleukin-6 has regenerative activities, which, when absent, aggravated the development of the inflammatory process. It turns out that regenerative or anti-inflammatory activities of IL- 6 are mediated by classic signaling, whereas pro-inflammatory responses of IL- 6 are mediated by trans-signaling.

Interleukin-6 is responsible for fever and causes growth of C-reactive protein (CRP) [6]. Interleukin-8 is a pro-inflammatory cytokine, which rises in response to IL-1 and tumor necrosis factor $\alpha$ (TNF- $\alpha$ ). Interleukin- 8 is a chemokine and causes migration of neutrophils to the place of inflammation, leading to pyuria in patients with UTI $[7,8]$. Increased serum and urine concentrations of IL- 6 and IL-8 were detected during the acute phase of UTI and in children in the UTI-free period with vesicoureteral reflux (VUR) and/ or renal scars (RS) [8-11].

Transforming growth factor $\beta 1$ (TGF- $\beta 1$ ) is an anti-inflammatory and pro-fibrotic cytokine. Transforming growth factor $\beta 1$ reduces concentrations of TNF- $\alpha$, IL-1, IL- 6 and IL-8, influences the function of leukocytes and macrophages, decreases their capacity to release toxic metabolites and enzymes, and reduces inflammation in acute pyelonephritis (APN). Transforming growth factor $\beta 1$ is a marker of fibrosis and it influences development of RS. In many kidney diseases TGF- $\beta 1$ is an indicator of progression of renal involvement [12-14]. A high urine concentration of TGF- $\beta 1$ was detected in children with obstructive uropathy, chronic kidney diseases and the acute phase of UTI [14-17].

The ${ }^{99 m}$ Tc-dimercaptosuccinic acid (DMSA) scan is the gold standard for diagnosing APN and RS [18]. Scintigraphy requires intravenous cannulation, involves radiation and is not available in all medical centers. It is also expensive. We are still trying to find noninvasive, diagnostic methods for assessment of renal parenchymal damage [19]. Potential targets are various biomarkers, which can be useful in diagnosis of UTI [20]. Unfortunately, previous results regarding IL-6 and IL-8 in serum and urine in children with UTI have been equivocal $[9,21]$. The role of TGF- $\beta 1$ in the acute phase of UTI is unclear [14, 22], and the number of trials assessing concentration of cytokines in ABU is limited [23, 24].

The aim of the study was to assess the usefulness of measurement of pro-inflammatory urine IL-6 and IL-8 levels and the anti-inflammatory TGF- $\beta 1$ level in infants with febrile UTI, non-febrile UTI and ABU.

\section{Material and methods}

The prospective study included 35 infants (age range: 1-12 months) admitted to the Department of Pediatric Nephrology with suspicion of the first-time UTI. Children were excluded from the study if they had concomitant febrile disease or evidence of obstructive nephropathy. On the day of admission urinalysis, urine culture, C-reactive protein (CRP), erythrocyte sedimentation rate (ESR) and white blood cell (WBC) count were checked. Urine samples were collected by suprapubic aspiration or catheterization. Leukocyturia was defined as $>5 \mathrm{WBC} /$ high power field in the urine sediment. Significant bacteriuria was defined as $>10^{5} /$ colony-forming units $/ \mathrm{ml}$ for catheterization and any growth for suprapubic aspiration [25]. A normal value of CRP in serum was $<1.0 \mathrm{mg} / \mathrm{dl}$, ESR $<15 \mathrm{~mm} / \mathrm{h}$, $\mathrm{WBC}<12,000 / \mathrm{mm}^{3}$. The diagnosis of UTI was based on clinical and laboratory criteria, including significant bacteriuria and leukocyturia; febrile UTI was diagnosed if fever $>38^{\circ} \mathrm{C}$ lasted at least 24 hours. Diagnosis of ABU was based on significant bacteriuria, normal urinalysis and no clinical symptoms of UTI. Urine samples were collected for measurement of IL- 6 , IL- 8 and TGF- $\beta 1$ during the first 48 hours after admission. Urine specimens were centrifuged and stored at $-80^{\circ} \mathrm{C}$. Cytokine levels were measured by enzyme-linked immunoassay (ELISA) kits (R\&D Systems, Inc., Minneapolis, Minnesota, USA). The lower limit of detection was $0.7 \mathrm{pg} / \mathrm{ml}$ for IL-6, $10 \mathrm{pg} / \mathrm{ml}$ for IL- 8 and $4 \mathrm{pg} / \mathrm{ml}$ for TGF- $\beta 1$. Cytokine to creatinine ratios were calculated to standardize samples and were expressed as $\mathrm{pg} / \mathrm{mg}$. Renal ultrasound was performed after admission in all children. A DMSA scan was performed in children with UTI during the first 10 days and voiding cystourethrography (VCUG) 2-3 weeks later. Based on the clinical manifestation and laboratory tests, children were divided into three groups: febrile UTI, non-febrile UTI and ABU. The study was approved by the Local Bioethics Committee. All parents gave their informed consent.

\section{Statistical methods}

Continuous variables were tested for normal distribution with Lilliefors and Shapiro-Wilk tests. Data were presented as the mean ( \pm standard deviation) or median (interquartile range). Parametric (Student's $t$-test, ANOVA test) or non-parametric (Mann-Whitney $U$ test, Kruskal-Wallis test) statistical analyses were used to compare continuous variables between groups. Categorical data were presented as absolute value and percentage. The chi-square test was used for the comparison of categorical variables. Correlations between variables were evaluated by Spearman rank coefficient. The receiver operating curves (ROCs) were determined and areas under the curves (AUCs) were calculated, including $95 \%$ confidence intervals (CIs), to determine the optimal cutoff values of cytokines to detect inflammatory changes in the DMSA scan. The sensitivity, specificity, and positive and negative predictive value (PPV and NPV, respectively) of cytokines were calculated. For all tests statistically significant $p$ values were $<0.05$. 
Statistical analysis was performed using the package Statistica ver. 10.0.

\section{Results}

A total of 35 children included $19(54 \%)$ boys and 16 $(46 \%)$ girls, mean age $6.14 \pm 347$ months. Febrile UTI was diagnosed in $13(37 \%)$ children, non-febrile UTI in $13(37 \%)$, ABU in 9 (26\%). Indications for urinalysis and urine culture in children with $\mathrm{ABU}$ included: failure to thrive (1), prolonged jaundice (1), abnormalities in urinary tract (2), and routine urine tests in 5 children. Escherichia coli was isolated in 33 (94\%) children, Proteus mirabilis in $1(3 \%)$ and Pseudomonas aeruginosa in $1(3 \%)$ child.

Comparison of clinical, laboratory and imaging results between children with febrile UTI, non-febrile UTI and $\mathrm{ABU}$ is presented in Table 1. Children with febrile and non-febrile UTI were significantly older than children with ABU. The number of girls with febrile UTI was signifi- cantly higher compared to the non-febrile UTI and ABU group. Urine IL- 6 and TGF- $\beta 1$ were detected significantly more frequently in children with febrile UTI than in ABU, and urine IL-8 in children with febrile UTI than in non-febrile UTI and ABU. Urine levels of IL-6 and IL-8 were significantly higher in the group with febrile UTI compared to those with non-febrile UTI and ABU, and urine levels of TGF- $\beta 1$ in the group with febrile UTI compared to those with ABU. Value of CRP, ESR and WBC were normal in children with $\mathrm{ABU}$ and significantly higher in children with febrile UTI compared to children with non-febrile UTI and ABU.

Correlations between urine IL-6, IL-8, TGF- $\beta 1$ and systemic inflammatory markers are presented in Table 2. Positive predictive correlations were found between IL-6 and IL- 8 , and between IL- 8 and TGF- $\beta 1$. Urine IL- 6 and IL-8 were positively correlated with CRP, ESR and WBC; TGF- $\beta 1$ was correlated only with WBC. Based on VCUG congenital abnormalities in kidney and urinary tract

Table 1. Comparison of clinical, laboratory and imaging findings between children with febrile urinary tract infection (UTI), non-febrile UTI and asymptomatic bacteriuria (ABU)

\begin{tabular}{|c|c|c|c|c|c|c|}
\hline \multirow[t]{2}{*}{ Variable } & \multicolumn{3}{|c|}{ Group } & \multicolumn{3}{|c|}{$p$} \\
\hline & $\begin{array}{c}\text { Febrile UTI } \\
\begin{array}{c}\text { I } \\
n=13\end{array} \\
\end{array}$ & $\begin{array}{c}\text { Non-febrile UTI } \\
\text { II } \\
n=13\end{array}$ & $\begin{array}{c}\text { ABU } \\
\text { III } \\
n=9\end{array}$ & I vs. II & I vs. III & II vs. III \\
\hline $\begin{array}{l}\text { Age (months); } \\
\text { mean } \pm \text { SD }\end{array}$ & $8.23 \pm 3.44$ & $6.15 \pm 2.97$ & $3.11 \pm 1.69$ & NS & $<0.01$ & $<0.05$ \\
\hline $\begin{array}{l}\text { Gender, } n(\%) \\
\text { Boys/girls }\end{array}$ & $\begin{array}{c}3 / 10 \\
(23 / 77)\end{array}$ & $\begin{array}{c}8 / 5 \\
(62 / 38)\end{array}$ & $\begin{array}{c}8 / 1 \\
89 / 11)\end{array}$ & $<0.05$ & $<0.01$ & NS \\
\hline$\uparrow \mathrm{IL}-6, n(\%)$ & $11(85)$ & $7(54)$ & $3(33)$ & NS & $<0.01$ & NS \\
\hline$\uparrow \mathrm{IL}-8, n(\%)$ & $11(85)$ & $5(38)$ & $2(22)$ & $<0.01$ & $<0.01$ & NS \\
\hline$\uparrow$ TGF- $\beta 1, n(\%)$ & $10(77)$ & $5(38)$ & $2(22)$ & NS & $<0.05$ & NS \\
\hline IL-6 (pg/mg)* & $\begin{array}{c}17.78 \\
(6.17 ; 48.74)\end{array}$ & $\begin{array}{c}1.59 \\
(0.00 ; 4.93)\end{array}$ & $\begin{array}{c}0.00 \\
(0.0 ; 0.91)\end{array}$ & $<0.05$ & $<0.01$ & NS \\
\hline IL-8 (pg/mg)* & $\begin{array}{c}132.58 \\
(64.41 ; 1177.97) \\
\end{array}$ & $\begin{array}{c}0.00 \\
(0.0 ; 81.32) \\
\end{array}$ & $\begin{array}{c}0.00 \\
(0.0 ; 0.0) \\
\end{array}$ & $<0.05$ & $<0.01$ & NS \\
\hline TGF- $\beta 1$ (pg/mg)* & $\begin{array}{c}35.51 \\
(2.29 ; 89.32)\end{array}$ & $\begin{array}{c}0.00 \\
(0.0 ; 67.66)\end{array}$ & $\begin{array}{c}0.00 \\
(0.0 ; 0.0)\end{array}$ & NS & $<0.05$ & NS \\
\hline $\mathrm{CRP}(\mathrm{mg} / \mathrm{dl})^{*}$ & $\begin{array}{c}7.46 \\
(2.67 ; 20.2)\end{array}$ & $\begin{array}{c}0.01 \\
(0.01 ; 0.01)\end{array}$ & $\begin{array}{c}0.01 \\
(0.01 ; 0.22)\end{array}$ & $<0.001$ & $<0.01$ & NS \\
\hline $\operatorname{ESR}(\mathrm{mm} / \mathrm{hour})^{*}$ & $\begin{array}{c}70.00 \\
(53.0 ; 90.0)\end{array}$ & $\begin{array}{c}10.00 \\
(4.0 ; 20.5)\end{array}$ & $\begin{array}{c}7.00 \\
(3.0 ; 10.0)\end{array}$ & $<0.001$ & $<0.001$ & NS \\
\hline $\begin{array}{l}\mathrm{WBC}\left(\mathrm{mm}^{3}\right) \\
\text { mean } \pm \mathrm{SD}\end{array}$ & $19.75 \pm 4.64$ & $15.22 \pm 4.55$ & $12.28 \pm 228$ & $<0.01$ & $<0.001$ & NS \\
\hline $\begin{array}{l}\text { CAKUT, } n(\%) \\
( \pm)\end{array}$ & $\begin{array}{c}5 / 8 \\
(38 / 62) \\
\end{array}$ & $\begin{array}{c}3 / 10 \\
(23 / 77) \\
\end{array}$ & $\begin{array}{c}2 / 7 \\
(22 / 78) \\
\end{array}$ & NS & NS & NS \\
\hline $\begin{array}{l}\text { DMSA, } n=18(\%) \\
( \pm)\end{array}$ & $\begin{array}{c}7 / 1 \\
(87.5 / 12.5)\end{array}$ & $\begin{array}{c}5 / 5 \\
(50 / 50)\end{array}$ & - & NS & - & - \\
\hline
\end{tabular}


Table 2. Correlations between urine IL-6, IL-8, TGF- $\beta 1$ and systemic inflammatory markers

\begin{tabular}{lcccccc}
\hline Variable & \multicolumn{2}{c}{ Interleukin-6 } & \multicolumn{2}{c}{ Interleukin-8 } & \multicolumn{2}{c}{ TGF- $\boldsymbol{\beta} \mathbf{1}$} \\
\cline { 2 - 7 } & $\boldsymbol{r}$ & $\boldsymbol{p}$ & $\boldsymbol{r}$ & $\boldsymbol{p}$ & $\boldsymbol{r}$ & $\boldsymbol{p}$ \\
\hline IL-6 & - & - & 0.57 & $<0.001$ & 0.29 & NS \\
\hline IL-8 & 0.57 & $<0.001$ & - & - & 0.39 & $<0.05$ \\
\hline TGF- $\beta 1$ & 0.29 & NS & 0.39 & $<0.05$ & - & - \\
\hline CRP & 0.58 & $<0.001$ & 0.58 & $<0.01$ & 0.24 & NS \\
\hline ESR & 0.60 & $<0.01$ & 0.47 & $<0.01$ & 0.29 & NS \\
\hline WBC & 0.55 & $<0.001$ & 0.46 & $<0.01$ & 0.48 & $<0.01$ \\
\hline
\end{tabular}

IL-6 - interleukin-6, IL-8 - interleukin-8, TGF- $\beta 1$ - transforming growth factor $\beta 1, C R P-C$-reactive protein, ESR - erythrocyte sedimentation rate, WBC-white blood cell count

(CAKUT) were diagnosed in $10(28.6 \%)$ children: in 5 with febrile UTI (4 - VUR grade 2, 1 - duplex kidney), in 3 with non-febrile UTI (3 - VUR grade 2$)$ and 2 with ABU (1 - VUR grade 2, 1 - ectopic kidney) (Table 1). There was no significant difference in frequency of CAKUT in the groups of patients. DMSA scan was performed in 18 (69\%) children with UTI. Inflammatory changes in kidneys were found in $12(66.6 \%)$ children. There were no significant differences in frequency of inflammatory changes in kidneys in children with febrile UTI compared to children with non-febrile UTI. Similarly, no significant differences in cytokine levels and value of systemic inflammatory markers were found in children with CAKUT compared to those without CAKUT and in children with an abnormal DMSA

A

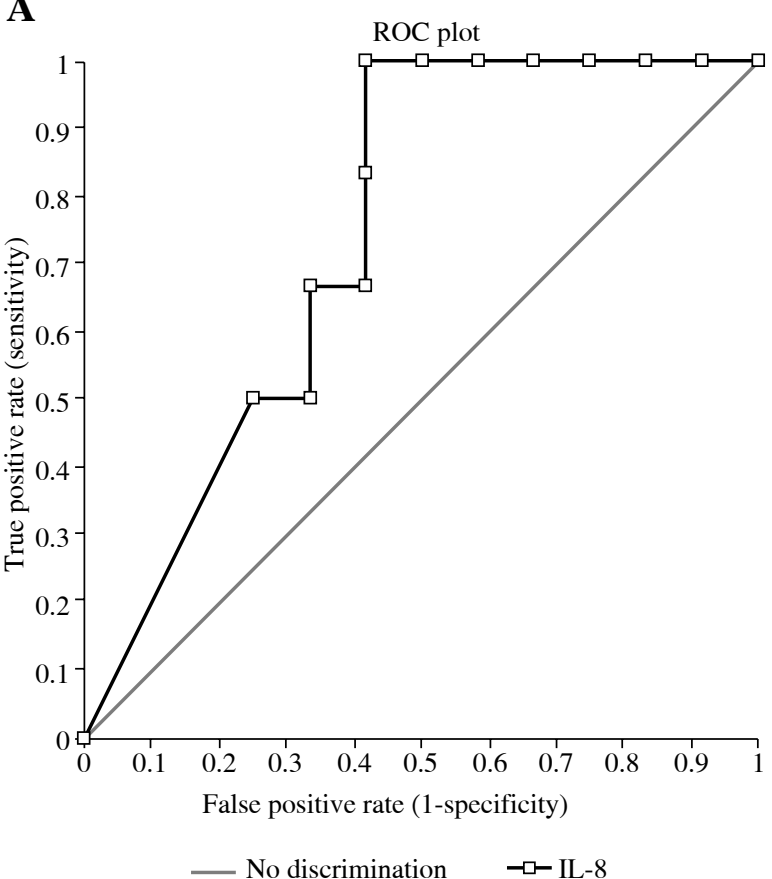

Table 3. Area under the curve (AUC) for urine IL-6, IL-8 and TGF- $\beta 1$ and systemic inflammatory markers to detect presence of inflammatory changes in DMSA scan

\begin{tabular}{lccc}
\hline Variable & AUC & Z test & $\boldsymbol{p}$ \\
\hline IL-6 & 0.56 (95\% CI: $0.27-0.84)$ & 0.38 & NS \\
\hline IL-8 & 0.74 (95\% CI: $0.52-0.97)$ & 2.12 & $<0.05$ \\
\hline TGF- $\beta 1$ & 0.76 (95\% CI: $0.56-0.97)$ & 2.55 & $<0.01$ \\
\hline CRP & 0.64 (95\% CI: 0.32-0.96) & 0.85 & NS \\
\hline ESR & 0.62 (95\% CI: $0.32-0.92)$ & 0.76 & NS \\
\hline WBC & 0.58 (95\% CI: $0.29-0.86)$ & 0.52 & NS \\
\hline
\end{tabular}

$\overline{I L-6}$ - interleukin-6, IL-8 - interleukin 8, TGF- $\beta 1$ - transforming growth factor $\beta 1, C R P-C$-reactive protein, ESR - erythrocyte sedimentation rate, $W B C-$ white blood cell count

B

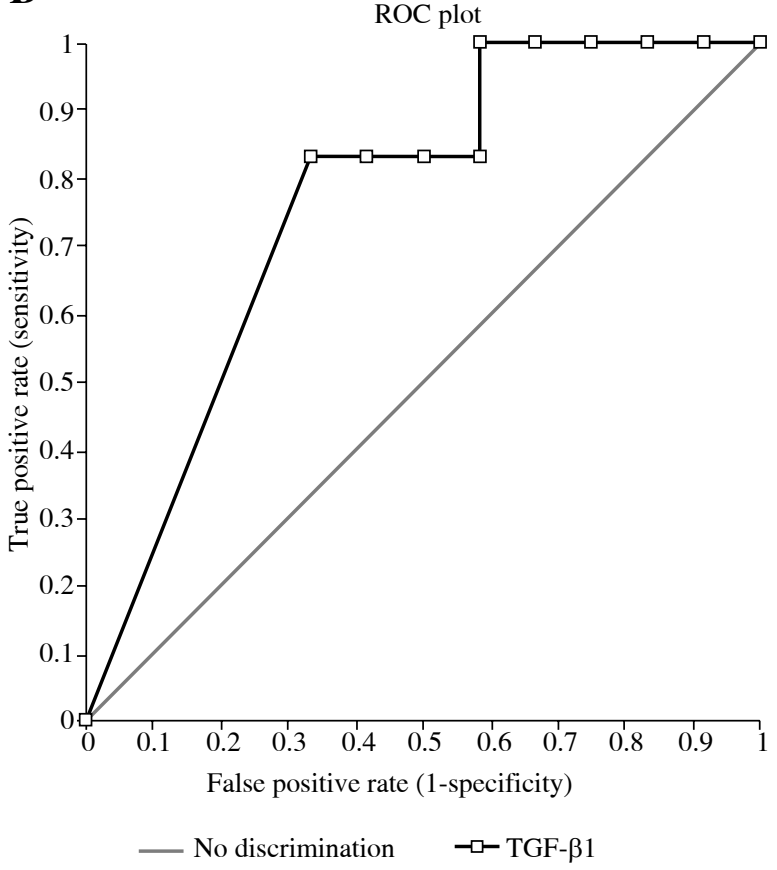

Fig. 1. Receiver operating curves (ROC) to detect presence of inflammatory changes in DMSA scan. A) ROC curve for urinary interleukin-8; B) ROC curve for urinary transforming growth factor $\beta 1$ 
scan compared to those with normal DMSA. Comparison of urine cytokine and systemic inflammatory markers to detect CAKUT and inflammatory changes in the DMSA scan reveled only a positive relation of CRP to CAKUT $(U=38.0, p<0.05)$. No other relations were documented.

Area under the curve (AUC) calculated with the ROC method for urine IL- 6 , IL- 8 , TGF- $\beta 1$ and systemic inflammatory markers to detect inflammatory changes in the DMSA scan is shown in Table 3. Area under the curve was significantly different for IL- 8 and TGF- $\beta 1$ (Fig. 1). The cutoff value of urine IL- 8 and TGF- $\beta 1$ to detect inflammatory changes in the DMSA scan was found to be $120 \mathrm{pg} / \mathrm{mg}$ for IL-8 and $40 \mathrm{pg} / \mathrm{mg}$ for TGF- $\beta 1$. Based on this value, the sensitivity for IL- 8 was $58.3 \%$, specificity $100.0 \%$, PPV $100.0 \%$ and NPV $54.5 \%$; for TGF- $\beta 1$ the values were $66.7 \%, 83.7 \%, 88.9 \%$ and $55.6 \%$, respectively.

\section{Discussion}

Clinical symptoms of UTI depend on the local and systemic host response to the presence of bacteria in the urinary tract. Release of high concentrations of serum and/ or urine pro-inflammatory cytokines induces a systemic response such as fever and increased inflammatory markers or a local response such as proteinuria, pyuria and erythrocyturia. In lower UTI, cytokines are released mainly to the urine, and therefore most patients have a normal temperature and systemic inflammatory markers [9]. Patients who are higher cytokine responders also have higher risk for APN. Patients who are lower cytokine responders often do not have symptoms of UTI and remain symptomless even if they have bacteria in the urinary tract [23]. Ragnarsdóttir et al. and Yun et al. found that the host's response to the presence of bacteria in the urinary tract can be genetically dependent. The polymorphism of the genes encoding the cytokines involved in UTI may influence the type of the host response [6, 26].

In the present study, the pro-inflammatory urine IL-6 was detected significantly more frequently in children with febrile UTI than in ABU, and urine IL- 8 significantly more frequently in children with febrile UTI than in non-febrile UTI and ABU. The cytokine responses were significantly higher in children with febrile UTI compared to children with non-febrile UTI and ABU. No significant differences in cytokine levels were documented between children with non-febrile UTI and ABU. Our findings are in agreement with the results of Benson et al., who evaluated 61 children with febrile UTI and 39 with ABU. In the Benson study, serum IL-6, urine IL-6 and IL-8 were detected significantly more frequently and were significantly higher in children with febrile UTI than in those with ABU [23]. In both studies, systemic inflammatory marker responses were significantly higher in children with febrile UTI compared to children with ABU and were positively correlated with cytokine levels. These results confirmed that bacterial infection may cause a local and generalized response in children with UTI and that IL- 6 and IL-8 play a crucial role for the inflammatory process in the urinary tract. In patients with $\mathrm{ABU}$ presence of bacteria in urine does not provoke an inflammatory response with no clinical signs. Both studies showed significant dominance of younger children and boys in the ABU group compared to the febrile UTI group. Probably ABU was associated with colonization of bacteria under the foreskin.

Fever and increased inflammatory markers are not reliable indicators of APN in infants with UTI. About 43-51\% of infants with febrile UTI have a normal DMSA scan, when performed in the acute phase of UTI [18, 27]. In children with APN systemic inflammatory markers are usually higher than in children with lower UTI [7, 9, 21]. However, the differences are not always statistically significant [28]. Shaikh et al. in a meta-analysis of 24 publications assessed the usefulness of procalcitonin (PCT), CRP and ESR in differential diagnosis of APN and lower UTI. Low CRP value $(<2.0 \mathrm{mg} / \mathrm{dl})$ was associated with low inflammatory changes in the DMSA scan (risk $<20 \%$ ). The value of ESR was not useful in the differential diagnosis of APN and lower UTI. The small number of studies with PCT did not allow reliable conclusions to be drawn [29]. In the previous study, we found significantly higher values of CRP and ESR in patients with changes in the DMSA scan, when compared to those with normal scintigraphy [30]. In the present study, we did not find a correlation between cytokines and DMSA scans.

In several studies, the usefulness of serum and urine IL-6 and IL-8 was assessed to detect inflammatory changes in the kidneys. Sheu et al. reported that serum and urine levels of IL-6 and IL-8 increased significantly more in APN than in lower UTI. The investigators found a significant, positive correlation between APN, cytokine levels and systemic inflammatory markers. Sensitivity of cytokines in diagnosis of renal parenchymal changes was lower than CRP, and specificity was similar to CRP [9]. In other studies, Spasojević et al. and Gürgöze et al. reveled significantly higher serum IL-6 levels in APN than in lower UTI [7, 28]. Gürgöze et al. did not confirm a correlation between APN and IL-6, which had lower sensitivity and higher sensitivity compared to CRP in diagnosis of APN. Rolidies et al. noted significantly increased IL-6 and IL-8 levels in urine, but not in serum, in neonates with APN. Only urine IL-6 was positively correlated with inflammatory changes in the DMSA scan [31]. In the study by Rodrigez et al. serum and urine IL-6 levels increased significantly more in APN than in lower UTI. Urine IL-6 showed lower sensitivity, but higher specificity in diagnosis of APN compared to serum IL-6 and CRP [32]. By contrast, Mahyar et al. found no difference in serum IL-6 and IL- 8 between children with febrile and non-febrile UTI, and no correlations between APN and cytokine levels. Sensitivity and specificity of cytokines in diagnosis 
of APN were much lower than CRP [21]. Similarly to our previous study, urine IL-6 and IL-8 were not related to inflammatory changes in the DMSA scan [30]. In the present study the cutoff for IL- 8 was $120 \mathrm{pg} / \mathrm{mg}$ and the sensitivity for detection of renal inflammatory changes in the DMSA scan was $58.3 \%$, and specificity was $100 \%$.

Anti-inflammatory cytokine down-regulates the pro-inflammatory cytokine response and limits the inflammatory process [14]. In the current study, urine TGF- $\beta 1$ was detected significantly more frequently and was significantly higher in children with febrile UTI compared to those with ABU. No other differences were documented between groups. However, we found a positive correlation between TGF- $\beta 1$ and IL- 8 and between TGF- $\beta 1$ and CRP. There was no correlation between TGF- $\beta 1$ and IL-6. Urine TGF- $\beta 1$ was not related to inflammatory changes in the DMSA scan. The cutoff of TGF- $\beta 1$ for detection of APN in scintigraphy was $40 \mathrm{pg} / \mathrm{mg}$, and sensitivity and specificity were $66.7 \%$ and $83.7 \%$, respectively.

In the study by Farmaki et al. urine TGF- $\beta 1$ was detected in about $50 \%$ of children with UTI and was undetected in healthy controls. It was detected more frequently and at significantly higher levels in children with normal DMSA compared to those with abnormal DMSA. Farmaki et al. postulated that the main function of TGF- $\beta 1$ in APN is prevention of inflammation. Higher levels of TGF- $\beta 1$ in children with a normal DMSA scan may limit inflammation [14]. By contrast, in the study by Galanakis et al. serum and urine TGF- $\beta 1$ were detected in children with APN and non-renal fever and urine TGF- $\beta 1$ levels were lower in infants with APN than in controls. It suggested a complex role of TGF- $\beta 1$ in the acute phase of infection [22].

The vesicoureteral reflux (VUR) is detected more frequently in children with APN than lower UTI $[9,28]$. However, the association between VUR and levels of cytokines in the acute phase of UTI is still controversial. Benson et al. reported that serum IL-6 level, but not IL-8, was significantly higher in children with VUR $\geq$ grade III, when compared to children without VUR or with VUR $\leq$ grade II [23]. Other investigators did not find an association between VUR and levels of IL-6 and IL-8 in serum and urine in the acute phase of UTI [28, 33-35]. In our previous study, we found a significantly higher urine IL-6 level in children with VUR compared to children without VUR [30]. In the current study there was no difference between levels of cytokines in children with or without VUR.

The concentration of cytokines in acute UTI depends on the severity of inflammation, virulence of bacteria, time of diagnosis, and day of treatment. Bacteria associated with UTI are usually strains with fimbriae, adhesins, siderophores, and capsules, that facilitate colonization of the urinary tract and lead to infection [26]. However, in most patients with $\mathrm{ABU}$, bacteria usually have low virulence. Benson et al. reported higher levels of IL-6 and IL-8 in urine in children with UTI caused by fimbriated $E$. coli compared to children with UTI caused by non-fimbriated $E$. coli, and fimbriated $E$. coli were detected only in a few patients with ABU (23). Diagnosis of UTI after a few days of fever is responsible for severe inflammation and high levels of cytokines in serum and urine. An appropriate treatment of UTI causes a reduction in the inflammatory process and a decrease in the levels of cytokines. Several studies have shown that after 48-72 hours of treatment, levels of pro-inflammatory cytokines were decreased [3638]. Anti-inflammatory cytokines are also produced for a short time at the acute time of infection and decrease after treatment. Farmaki et al. found that the urine TGF- $\beta 1$ level obtained in the first 12 hours of treatment is approximately two times higher than that obtained between 12 and $24 \mathrm{~h}$ after initiation of treatment. In Farmaki's opinion, TGF- $\beta 1$ can play an important role in regression of inflammatory changes and repairing parenchyma in the very early phase of UTI [14]. Mohkam et al. and Gorczyca et al. did not confirm a rapid decrease of the cytokine levels in children with UTI $[35,39]$. In our patients, samples of urine were obtained in the first 48 hours from admission, and in some patients also after initiation of treatment. It may have influenced the levels of cytokines. Tramma turned his attention to the method of cytokine measurement in various studies [40]. Some investigators indicated that age and gender of a child may influence the cytokine levels. Benson et al. found that urine IL- 6 and IL- 8 responses were higher in girls than in boys and urine IL-6 increased significantly with age [23]. However, other researchers did not report differences between serum and urine IL- 6 and urine IL- 8 and TGF- $\beta 1$ levels in relation to age and gender $[22,33,37,38]$.

Delayed diagnosis of APN may increase inflammatory changes in the renal parenchyma. Doganis et al. found inflammatory changes in the DMSA scan in $41 \%$ of infants with febrile UTI treated on the first day of fever and in $75 \%$ of children treated after 4 days of fever or later [18]. In $25-51 \%$ of infants with APN renal scars are detected in the DMSA scan $[18,27,41]$. Importantly, clinical symptoms of UTI are not accurate predictors of development of renal scars in the future. Similarly, in many studies, concentrations of serum IL-6, urine IL-6 and IL- 8 in children with UTI did not correlate with renal scars in the acute phase of infection [28, 33, 38, 41].

\section{Conclusions}

The present study revealed that pro- and anti-inflammatory cytokines play a crucial role in the acute phase of UTI. We found significant differences in children with febrile UTI and ABU regarding urine IL-6, IL-8, and TGF- $\beta 1$ levels and the value of systemic inflammatory markers, as well as significant differences in children with febrile and non-febrile UTI, regarding IL-6, IL-8 and 
serum inflammatory markers. Inflammatory changes in the DMSA scan were revealed in $66.6 \%$ of children with UTI. No significant differences in frequency of abnormal DMSA scan were found in the group with febrile and non-febrile UTI. No associations between urine cytokines, systemic inflammatory markers and changes in the DMSA scan were documented. A limitation of our study was the small number patients in groups, which allowed the cutoff for detection of inflammatory changes in the DMSA scan to be designated only for IL- 8 and TGF- $\beta 1$. Sensitivity for cytokines in APN was low, but specificity was high. Urine and systemic inflammatory markers do not differentiate between upper and lower UTI in infants.

\section{The authors declare no conflict of interest.}

\section{References}

1. Hansson S, Bollgren I, Esbjörner E, et al. (1999): Urinary tract infections in children below two years of age: a quality assurance project in Sweden. Acta Paediatr 88: 270-274.

2. American Academy of Pediatrics. Committee on Quality Improvement. Subcommittee on Urinary Tract Infection Practice Guideline (1999): The diagnosis, treatment, and evaluation of the initial urinary tract infection in febrile infants and young children. Pediatrics 103: 843-852.

3. Wettergren B, Jodal U (1990): Spontaneous clearance of asymptomatic bacteriuria in infants. Acta Pediatr Scand 79: 300-304.

4. Tullus K (2011): Difficulties in diagnosing urinary tract infections in small children. Pediatr Nephrol 26: 1923-1926.

5. Raz R (2003): Asymptomatic bacteriuria. Clinical significance and management. Int J Antimicrob Agents 22 (Suppl. 2): S45-S47.

6. Ragnarsdóttir B, Svanborg C (2012): Susceptibility to acute pyelonephritis or asymptomatic bacteriuria: host-pathogen interaction in urinary tract infections. Pediatr Nephrol 27: 2017-2029.

7. Gürgöze MK, Akarsu S, Yilmaz E, et al. (2005): Proinflammatory cytokines and procalcitonin in children with acute pyelonephritis. Pediatr Nephrol 20: 1445-1448.

8. Gokce I, Alpay H, Biyikli N, et al. (2010): Urinary levels of interleukin- 6 and interleukin- 8 in patients with vesicoureteral reflux and renal parenchymal scar. Pediatr Nephrol 25: 905-912.

9. Sheu JN, Chen MC, Lue KH, et al. (2006) Serum and urine levels of interleukin- 6 and interleukin- 8 in children with acute pyelonephritis. Cytokine 36: 276-282.

10. Zarkesh M, Sedaghat F, Heidarzadeh A, et al. (2014): Diagnostic value of IL-6, CRP, WBC and absolute neutrophil count to predict serious bacterial infection in febrile infants. Acta Med Iran 53: 408-411.

11. Galanakis E, Bitsori M, Dimitriou H, et al. (2006): Urine interleukin-8 as a marker of vesicoureteral reflux in infants. Pediatrics 117: e863-e867.

12. Chen X, Zhu W, Al-Hayek S, et al. (2015): Urinary TGF-1 has a supplementary value in predicting renal function recovery post unilateral ureteral obstruction. Int Urol Nephrol 47: 33-37.
13. Cotton SA, Gbadegesin RA, Williams S, et al. (2002): Role of TGF- $\beta 1$ in renal parenchymal scarring following childhood urinary tract infection. Kidney Int 61: 61-67.

14. Farmaki E, Papachristou F, Winn RM, et al. (2005): Transforming growth factor- $\beta 1$ in the urine of young children with urinary tract infection. Pediatr Nephrol 20: 180-183.

15. Mandelia A, Bajpai M, Agarwala S, et al. (2013): The role of urinary TGF- $\beta 1$, TNF- $\alpha$, IL- 6 and microalbuminuria for monitoring therapy in posterior urethral valves. Pediatr Nephrol 28: 1991-2001.

16. Zieg J, Blahova K, Seeman T, et al. (2011): Urinary transforming growth factor- $\beta 1$ in children with obstructive uropathy. Nephrology 16: 595-598.

17. Grenda R, Wühl, Litwin M, et al. (2007): Urinary excretion of endothelin-1 (ET-1), transforming growth factot-beta1 (TGF-beta1) and vascular endothelial growth factor (VEGF165) in paediatric chronic kidney diseases: results of the ESCAPE trial. Nephrol Dial Transplant 22: 3487-3494.

18. Doganis D, Siafas K, Mavrikou M, et al. (2008): Does early treatment of urinary tract infection prevent renal damage? Pediatrics 120: e922-e928.

19. Jobs K, Straż-Żebrowska E, Placzyńska M, et al. (2014): Interleukin-18 and NGAL in assessment of ESWL treatment safety in children with urolithiasis. Cent Eur J Immunol 39: 384-391.

20. Lee HE, Kim DK, Kang HK, et al. (2015): The diagnosis of febrile urinary tract infection in children may be facilitated by urinary biomarkers. Pediatr Nephrol 30: 123-130.

21. Mahyar A, Ayazi P, Maleki MR, et al. (2013): Serum levels of interleukin- 6 and interleukin- 8 as diagnostic markers of acute pyelonephritis in children. Korean J Pediatr 56: 218-223.

22. Galanakis E, Bitsori M, Dimitriou H, et al. (2007): Serum and urine interleukin-6 and transforming growth factor-beta1 in young infants with pyelonephritis. Int Urol Nephrol 39: 581-585.

23. Benson M, Jodal U, Agace W, et al. (1996): Interleukin (IL)-6 and IL-8 in children with febrile urinary tract infection and asymptomatic bacteriuria. J Infect Dis 174: 1080-1084.

24. Kjölvmark C, Tschernij E, Öberg J, et al. (2016): Distinguishing asymptomatic bacteriuria from urinary tract infection in the elderly - the use of urine levels of heparin-binding protein and interleukin-6. Diagn Microbiol Infect Dis 85: 243-248.

25. Mishra OP, Abhinay A, Prasad R (2013): Urinary infection in children. Indian J Pediatr 80: 838-843.

26. Yun KW, Kim HY, Park HK, et al. (2014): Virulence factors of uropathogenic Escherichia coli of urinary tract infections and asymptomatic bacteriuria in children. J Microbiol Immunol Inf 47: 455-461.

27. Pecile P, Miorin E, Romanello C, et al. (2009): Age-related parenchymal lesions in children with first febrile urinar tract infections. Pediatrics 124: 23-29.

28. Spasojević-Dimitrijeva B, Živkowić M, Stankowić A, et al. (2010): The IL-6-174G/C polymorphism and renal scarring in children with first acute pyelonephritis. Pediatr Nephrol 25: 2099-2106.

29. Shaikh N, Borrell JL, Evron J, Leeflang MM (2015): Procalcitonin, C-reactive protein, and erythrocyte sedimentation rate for diagnosis of acute pyelonephritis in children. Cochrane Database Syst Rev 1: CD009185.

30. Roilidies E, Papachristou F, Gioulekas E, et al. (1999): Increased urine interleukine- 6 concentrations correlate with pyelonephitic changes on $99 \mathrm{mTc}$-dimercaptosuccinic acid 
scan in neonates with urinary tract infections. J Infect Dis 180: 904-907.

31. Rodriguez LM, Robles B, Marugán JM, et al. (2008): Urinary interleukin-6 is useful in distinguishing between upper and lower urinary tract infections. Pediatr Nephrol 23: 429-433.

32. Krzemień G, Roszkowska-Blaim M, Kostro I, et al. (2004): Urinary levels of interleukin- 6 and interleukin- 8 in children with urinary tract infections to age 2. Med Sci Monit 10: CR593-597.

33. Sheu JN, Chen MC, Chen SM, et al. (2009): Relationship between serum and urine interleukin- 6 elevations and renal scaring in children with acute pyelonephritis. Scan J Urol Nephrol 43: 133-137.

34. Mahyar A, Ayazi P, Yarigarravesh MH, et al. (2015): Serum interleukin- 8 is not a reliable marker for prediction of vesicoureteral reflux in children with febrile urinary tract infection. Int Braz J Urol 41: 1160-1166.

35. Mohkam M, Karimi A, Karimi H, et al. (2008): Urinary interleukin-8 in acute pyelonephitis of children: a before-after study. Iran J Kidney Dis 2: 193-196.

36. Kassir K, Vargas-Shiraishi O, Zaldivar F, et al. (2001): Cytokine profiles of pediatric patients treated with antibiotics for pyelonephritis: potential therapeutic impact. Clin Diagn Lab Immunol 8: 1060-1063.

37. Jantausch BA, O'Donnell R, Wiedermann BL (2000): Urinary interleukin- 6 and interleukin- 8 in children with urinary tract infection. Pediatr Nephrol 15: 236-240.

38. Renata Y, Jassar H, Katz R, et al. (2013): Urinary concentration of cytokines in children with acute pyelonephritis. Eur J Pediatr 172: 769-774.

39. Gorczyca D, Augustyniak D, Basiewicz-Worsztynowicz B, Karnas-Kalemba W (2014): Serum and urinary MIP- $1 \alpha$ and IP-10 levels in children with urinary tract infections. Adv Clin Exp Med 23: 933-938.

40. Tramma D, Hatzistylianou M, Gerasimou G, Lafazanis V (2012): Interleukin-6 and interleukin-8 levels in the urine of children with renal scarring. Pediatr Nephrol 27: 1525-1530.

41. Rodríguez LM, Robles B, Marugán JM, et al. (2013): Do serum C-reactive protein and interleukin-6 predict kidney scarring after urinary tract infection? Indian J Pediatr 80: 1002-1006. 